\section{Response of carpal tunnel syndrome to hormone replacement therapy}

\section{Ronit Confino-Cohen, Michael Lishner, Hillel Savin, Ruth Lang, Mordchai Ravid}

Sackler Faculty of

Medicine, Tel Aviv

University and

Meir Hospital, Kfar Saba

44281, Israel

Ronit Confino-Cohen, MD,

registrar

Michael Lishner, MD, associate head, department of medicine

Hillel Savin, MD, consultant in rheumatology

Ruth Lang, MD, consultant, department of medicine Mordchai Ravid, MD, associate professor of medicine

Correspondence to:

Dr M Lishner, Department of Medicine, Meir Hospital, Kfar Saba 44281, Israel.

$B M \gamma$ 1991;303:1514
Department of Medicine,
The carpal tunnel syndrome is five times more common in women than in men $^{1}$; it is found most often in women aged over 40 and is therefore common postmenopausally. The ultimate form of treatment is surgical relief of nerve entrapment. ${ }^{2}$ There is, however, general agreement that conservative measures should be tried first. These include mainly splinting, injection of steroids into the carpal tunnel, and nonsteroidal anti-inflammatory agents. ${ }^{23}$ Treatment with vitamin B-6 has also been advocated, but the therapeutic effect was not corroborated by controlled studies. ${ }^{34}$

We describe two women with severe carpal tunnel syndrome unresponsive to medical treatment, whose symptoms resolved unexpectedly soon after starting hormone replacement therapy for their menopausal symptoms.

\section{Case reports}

Case 1-A 52 year old healthy woman had a six month history of numbness and pain in both hands. Examination showed paresthesia in the distribution area of the median nerve. Electromyography confirmed the severity of the disease. Non-steroidal antiinflammatory agents gave no relief, and she was referred for surgical release of the entrapped nerve. While waiting for surgery and independently of the carpal tunnel syndrome, cyclic hormone replacement therapy (conjugated oestrogen $0.625 \mathrm{mg} /$ day for 25 consecutive days and medroxyprogesterone acetate $5 \mathrm{mg} /$ day for the last 13 days) was started for her climacteric symptoms. A gradual alleviation of her carpal tunnel symptoms followed, and the pain and numbness resolved completely about three weeks subsequently. Surgery was withheld; she was subsequently followed up for 20 months and remained asymptomatic. An interruption of oestrogen treatment for three months did not exacerbate her symptoms.

Case 2-A 54 year old healthy housewife was examined because of typical complaints of the carpal tunnel syndrome in both hands. At the age of 47 she had had a panhysterectomy because of uterine bleeding due to a submucosal myoma. Pain and numbness began in both hands at the age of 48. Electromyography disclosed findings typical of the syndrome, and after failure of conservative measures division of the left transverse carpal ligament was performed. The outcome of surgery was poor, and she did not submit for surgery of the other hand. At the age of 50 substitution hormone therapy was started. The pain in her hands regressed gradually over several weeks subsequently until both hands became free of pain. During the subsequent three years hormone therapy was interrupted on several occasions for three to four months. Consistently, pain and numbness recurred shortly after cessation of the hormone therapy, only to resolve once the treatment was renewed.

\section{Comment}

Although a temporal relation between the onset of the menopause and the carpal tunnel syndrome has been reported, ${ }^{1}$ the effect of hormone replacement on the syndrome has not been referred to. In these two patients the beneficial effect of combined oestrogen and progesterone therapy on the symptoms of the carpal tunnel syndrome was unequivocal. In the second patient the typical pain and numbness recurred within sa fortnight whenever the hormone therapy was interrupted and responded readily, within days, to its reinstitution. The prompt response may indicate the therapeutic role of oestrogen, which was the firs hormone to be given, whereas the progesterone followed 12 to 14 days later. Repeat electromyography was not performed; however, since the indication for surgical intervention is clinical, irrespective of the electromyographic pattern,${ }^{1}$ the favourable response to the hormone therapy allowed surgery to be avoided.

Speculation about the mechanism of action of oestrogen is premature. Since the syndrome is common in menopausal women the possible therapeutic effect of hormone replacement therapy should be established by controlled clinical studies.

1 Milford L. Carpal tunnel and uinar tunnel syndromes and stenosing tenosynovitis. In: Crenshaw AH, ed. Campbell's operative orthopaedics. 7th ed. St Louis, Missouri: C V Mosby, 1987:459-68.

2 Kulick MI, Gordillo G, Javidi T. Long-term analysis of patients having surgica treatment for carpal tunnel syndrome. F Hand Surg [Am] 1986;11:59-66.

3 Amadio PC. Pyridoxine as an adjunct in the treatment of carpal tunnel syndrome. 7 Hand Surg $[A m] 1985 ; 10: 237-41$.

4 Stransky $M$, Rubin A, Lava NS, Lazaro RP. Treatment of carpal tunne syndrome with vitamin B: a double-blind study. South Med f 1989;82:841-2.

(Accepted 12 fuly 1991)
Department of Geriatric Medicine, Arrowe Park Hospital, Wirral L49 5PE

J M Nankhonya, MRCP, registrar

C J Turnbull, MRCP,

consultant

Department of Behavioura

Sciences, Salford

University, Salford

M6 6PU

$\mathrm{J} \mathrm{T}$ Newton, BA, lecturer in statistics

Correspondence to: Dr J M Nankhonya, 24 Colmore Avenue, Spital, Wirral L63 9NL.

\section{Social and functional impact of minor fractures in elderly people}

\section{J M Nankhonya, C J Turnbull, J T Newton}

An acute illness can suddenly threaten an elderly patient's social and functional independence. Fractures can be particularly disabling because of pain and the use of splints. Studies on hip fractures culminated in recommendations by the Royal College of Physicians.' Minor fractures, which we define as fractures not severe enough to merit inpatient treatment, occur more commonly than major ones, but little is known of their effects on the overall wellbeing of patients in the community. We assessed the impact of minor fractures on elderly patients' activities of daily living and the effectiveness of current policies for providing social support.

\section{Patients, methods, and results}

We performed a prospective study in the fracture clinic in a district general hospital. Patients aged 70 or over with minor fractures who had not been admitted to hospital but were attending the clinic were interviewed by one of us (JMN). Information on demography, the site of the fracture, functional ability, and social circumstances before and after the fracture was recorded. Patients from nursing and residential homes were excluded. Functional ability was assessed with the modified Barthel activities of daily living index. ${ }^{2}$

We interviewed 116 patients, of whom 11 were excluded. The mean age of the 105 eligible patients was 77 (range 70-89), and 93 were women. Thirty six lived alone, 53 lived with somebody aged 65 or over, and 11 lived with somebody aged less than 65 ; five lived in warden controlled accommodation. The table shows the functional scores in relation to the site of fracture.

Eleven patients received statutory home help after a median wait of eight days (range 5-20). Four patients $\frac{0}{0}$

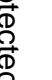

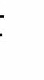

